\title{
Immunogenicity of an Inactivated Novel Duck Parvovirus Vaccine for Short Beak and Dwarf Syndrome in Cherry Valley Ducks
}

\section{Jiewen Zhou}

China Agricultural University

\section{Chuangfeng Li}

Shanghai Veterinary Research Institute Chinese Academy of Agricultural Sciences

\section{Aoxing Tang}

Shanghai Veterinary Research Institute Chinese Academy of Agricultural Sciences

\section{Hang Li}

Shanghai Veterinary Research Institute Chinese Academy of Agricultural Sciences

\section{Zhaorong Yu}

Shanghai Veterinary Research Institute Chinese Academy of Agricultural Sciences

\section{Zongyan Chen}

Shanghai Veterinary Research Institute Chinese Academy of Agricultural Sciences

\section{Xin Guo}

China Agricultural University

Guangqing Liu ( $\nabla$ liugq@shvri.ac.cn )

Shanghai Veterinary Research Institute Chinese Academy of Agricultural Sciences https://orcid.org/0000-0002-7116-3689

\section{Research Article}

Keywords: Novel duck parvovirus, duck short beak and dwarf syndrome, inactivated vaccine, immunogenicity

Posted Date: August 18th, 2021

DOI: https://doi.org/10.21203/rs.3.rs-791502/v1

License: (c) (1) This work is licensed under a Creative Commons Attribution 4.0 International License. Read Full License 


\section{Abstract}

Duck short beak and dwarf syndrome (SBDS) is a viral infectious disease caused by novel duck parvovirus (NDPV). It has brought serious economic losses to the Chinese duck industry in recent years. Currently, there exists no effective vaccine against this disease. In this study, we developed an inactivated virus vaccine based on NDPV-DS15 for SBDS. Immune efficacy was evaluated in 112 ducks, which were randomly divided into vaccination, challenge control, vaccination-challenge, and blank control groups ( $\mathrm{n}$ = 28 each). Clinical characteristics, antibodies, viral excretion, viremia, and pathological changes were monitored and analyzed. No morbidity or death was observed in the immunized ducks, which showed normal weight and good mental state. High levels of serum antibodies $\left(\mathrm{OD}_{450 \mathrm{~nm}}: \sim 0.63\right)$ were detected in ducks immunized with inactivated vaccine at 7 days post-vaccination (dpv), and the amount of virus neutralizing antibodies increased from $1: 2^{3}$ to $1: 2^{8.5}$ from $7 \mathrm{dpv}$ to $42 \mathrm{dpv}$. The anal swab, serum, and tissue viral load tests showed that vaccination could significantly inhibit the replication of NDPV in immunized ducks. Moreover, NDPV could not be isolated from the spleens of immunized or vaccinationchallenged ducks. Our results show that the developed inactivated NDPV vaccine, administered in an oil emulsion adjuvant, possesses good immunogenicity and represents a potentially powerful tool for SBDS prevention and control.

\section{Introduction}

As early as the 1970s, duck short beak dwarf syndrome (SBDS), caused by goose parvovirus (GPV), was reported in European countries [12]. The main hosts, Muscovy and hybrid Muscovy ducks, exhibit short beaks and severe growth retardation in $10-30 \%$ of affected ducks $[12,14]$. In 1990, the Taiwan region of China reported the occurrence of SBDS caused by a mixed viral infection of Muscovy duck parvovirus and duck hepatitis virus [10]. At the end of 2014, duck SBDS caused by novel duck parvovirus (NDPV) appeared on duck farms in many provinces and regions in China, which was mainly characterized by skeletal developmental obstacles and severe growth retardation in Cherry Valley ducks, Pekin ducks, mule ducks, and sheldrakes $[1,2,8,11,18]$. The mortality rate of this disease is not high $(2-6 \%)$, but the disabling elimination rate can reach $50 \%$, causing serious economic losses to the duck industry [9]. The disease is still prevalent in some areas, and can be mixed with other virus[5]. At present, there exists no effective vaccine to prevent and control the disease.

Studies have shown that NDPV isolates are more pathogenic to ducks than classical GPV isolates $[2,11]$. NDPV not only evolves at a much higher rate than GPV, but also possesses a higher rate of transmission than GPV [3]. This demonstrates the evolutionary dominance of this pathogen and the threat it poses to the duck breeding industry, which cannot be underestimated. Hence, there is an urgent need to develop a vaccine that can prevent and control SBDS.

Although genome sequences and amino acid sequences of NDPV are more than $90 \%$ homologous to those of GPV, there still exist differences in key amino acids, such as a change from Ser to Asn at positions 489 and 650 in NDPV, and mutations at positions 7, 116, 366, and $444[3,8]$, which may result 
in the GPV vaccines to protect ducks against SBDS less effectively. Therefore, the protective efficacy of the GPV vaccine needs to be systematically validated in ducks.

More extensive research has been conducted on the prevention and control of gosling plague, including testing of attenuated and inactivated vaccines. Although attenuated vaccines can stimulate the body to produce an immune response more quickly, their safety is still an issue, which cannot be ignored. There is a risk of the attenuated strain returning to a virulent strain as well as the possibility of recombination with other virulent strains to form new strains with stronger pathogenicity. The causative pathogen of duck SBDS, which was prevalent in 2019 in Linwu, Hunan, was a recombinant NDPV strain composed of NGPV sdlc01, GPV Y, and the vaccine strain SYG61v [16]. SDLY1602, isolated in Shandong, has been shown to be a recombinant strain formed by the involvement of the primary parental GPV vaccine strain 82-0321v and the secondary parental GPV wild strain GDaGPV [9]. In addition, anti-GPV egg yolk antibodies are clinically used for controlling the disease, but there could be biosafety risks associated with the use of goose egg yolk antibodies for the prevention and control of duck diseases. Therefore, in view of the current situation, the development of an inactivated NDPV vaccine for ducks having SBDS is still the first choice for the prevention of SBDS.

In this study, we developed an inactivated virus vaccine based on NDPV-DS15 for SBDS and tested its efficacy in 112 ducks, which were randomly divided into vaccination, challenge control, vaccinationchallenge, and blank control groups.

\section{Materials And Methods}

\subsection{Preparation of seed NDPV for challenge and vaccination}

One-day-old embryonated Cherry Valley duck eggs were purchased from a commercial hatchery located in Hangzhou, Zhejiang Province, China. No SBDS has ever been recorded in this area. The NDPV-DS15 strain was originally isolated in 2015, from Anhui province of China from a 4-week-old Cherry Valley duck exhibiting signs typical of SBDS. DS15 was continuously passaged to the second generation in 9-day-old embryonated Cherry Valley duck eggs, and NDPV-DS15-F2 was named as the challenge strain, which in turn was continuously passaged to the 20th generation and used as the vaccine strain in this study. Clarified suspensions of allantoic fluid and embryos from dead embryonated Cherry Valley duck eggs were obtained from 3- to 6-days post-inoculation as described previously [17].

\subsection{Preparation of inactivated NDPV-DS15 vaccine}

The allantoic fluid from ducks harboring the 20th generation DS15 strain was used to produce the inactivated virus vaccine. Suspensions containing NDPV were mixed with an inactivator, $2 \%$ o $\beta$ propiolactone, and then incubated at $4^{\circ} \mathrm{C}$ for $24 \mathrm{~h}$ to inactivate the virus before hydrolysis at $37^{\circ} \mathrm{C}$ for $2 \mathrm{~h}$. The above-mentioned solution, as the aqueous phase, was emulsified with Montanide ISA $71 \mathrm{VG}$, as the oil phase, at a ratio of 35:65; the final oil emulsion inactivated NDPV vaccine was milky white in color.

\subsection{Clinical scoring and NDPV load detection and isolation}


In total, 112 ducklings were randomly divided into four groups $(n=28)$ : vaccination $(V)$, challenge control $(\mathrm{C})$, vaccination-challenge $(\mathrm{V} / \mathrm{C})$, and blank control (B) groups. The timing and dosage of vaccination and challenge, and collection of anal swab, serum, and tissue samples from ducklings in each group are described in Table 1. Clinical symptoms were observed and scored, and DNA was extracted from the samples (tissue, serum, and anal swab) using an E.Z.N.A. ® Tissue DNA Kit (Omega Bio-tek, Inc., Norcross, GA, USA). The NDPV load was quantified using $20 \mathrm{ng}$ DNA and an NDPV quantitative real-time PCR (qPCR) assay, as described previously [20].

The tissue with the highest viral load would be used for the isolation of NDPV. The tissue was homogenized in $0.01 \mathrm{M}$ PBS solution and filtered through a $0.22 \mu \mathrm{m}$ filter. Nine-day-old embryonated Cherry Valley duck eggs were inoculated with the tissue filtrate, and pathological lesions in embryos that died at 36-120 h were observed. PCR was subsequently performed on DNA extracted from the allantoic fluid of the dead embryonated eggs using a pair of NDPV identification primers ( $\mathrm{F}: 5^{\prime}-$ CCGGGTAGACCAGAAATGTAA-3' and R: 5'-TAATTGTTCCTGCTTCTCTTAG-3').

\subsection{Detection of antibodies in duck serum}

VP3 is a major structural protein of parvoviruses [19]. NDPV-VP3-specific antibodies were analyzed using a NDPV-VP3-based enzyme-linked immunosorbent assay (ELISA), which was established in our laboratory. Serum samples were inactivated at $56^{\circ} \mathrm{C}$ for $30 \mathrm{~min}$, diluted at 1:100 in $5 \%$ PBS, and the absorbance was measured at $450 \mathrm{~nm}$ using an ELISA microplate reader (Aosheng, Hangzhou, China).

Virus neutralizing (VN) antibodies were tested as follows: serum samples were inactivated at $56^{\circ} \mathrm{C}$ for 30 min and then a 2-fold dilution was performed sequentially. Subsequently, the diluted samples were mixed with an equal volume of culture medium containing $200 \mathrm{ELD}_{50}$ (50\% embryo lethal dose) of NDPV. The mixtures were incubated at $37^{\circ} \mathrm{C}$ for $1 \mathrm{~h}$ and then injected into 9-day-old embryonated Cherry Valley duck eggs. The eggs were incubated for 7 days in an incubator with $50 \%$ humidity at $37^{\circ} \mathrm{C}$, during which the number of duck embryo deaths per dilution was recorded. The $50 \%$ neutralization endpoint for each serum sample was calculated using the method described by Reed and Muench [7].

\subsection{Histopathological examination}

Tissues were fixed in $4 \%$ neutral formalin at $24{ }^{\circ} \mathrm{C}$ for $48 \mathrm{~h}$, dehydrated with ethanol, cleared with xylene, embedded in paraffin, and sectioned into $4 \mu \mathrm{m}$-thick sections. After deparaffinization, the sections were stained with hematoxylin and eosin (H\&E). Pathological changes were scanned and observed using a 3D histochemical scanner (Pannoramic 250; 3DHISTECH, Budapest, Hungary).

\subsection{Statistical analysis}

Data are presented as the mean \pm standard deviation (SD). For comparison of groups, we used GraphPad Prism software version 7.00 (GraphPad Software Inc., San Diego, CA, USA). Statistical significance was set at $p<0.05$. 


\section{Results}

\subsection{ELD ${ }_{50}$ of NDPV for the challenge and vaccine strains}

The virulent challenge strain used in this experiment was NDPV-DS15-F2 and the vaccine strain was NDPV-DS15-F20. The ELD 50 values of the virulent challenge and vaccine strains were $10^{-4.75} / 0.2 \mathrm{~mL}$ and $10^{-5.5} / 0.2 \mathrm{~mL}$, respectively.

\subsection{Vaccination protects the ducks from significant pathological changes}

After immunization and challenge, ducks in the V group showed no obvious pathological changes, maintained normal feeding, and were in good mental condition. In contrast, ducks in the V/C group showed no significant difference from the B group, except for one duck that showed an easy fracture of the leg bone after the challenge. The $\mathrm{C}$ group showed obvious pathological changes after 2 weeks of challenge, especially in the form of serious growth retardation and easy fracture of the leg bones, two of which symptoms were more severe and caused paralysis. This was in addition to other symptoms, such as disheveled feathers, diarrhea, and mental atrophy (Table 2).

There was no significant difference between the body weights of ducks in the $\mathrm{V}$ and $\mathrm{V} / \mathrm{C}$ groups and that of ducks in the $B$ group at any time point. In contrast, the $C$ group showed a significant weight loss of $16.8-17.6 \%$ at 22 days of age (14 days post-infection [dpi]) compared with the weight of ducks in the $V$ and B groups, and a further weight loss of $23.3 \sim 27.4 \%$ at 43 days of age (35 dpi, Fig. 1).

\subsection{Immunization with the vaccine inhibits NDPV replication}

No significant differences in NDPV load were observed between anal swabs, serum, or tissues of ducks in the $V$ and $B$ groups. Anal swab viral load detection revealed that the duration of virus excretion was shortened and delayed, and the amount of virus excretion was decreased in the $\mathrm{V}$ group compared with that in the $\mathrm{C}$ group. In the V/C group, significantly lower viral loads were detected only at $3 \sim 21 \mathrm{dpi}$, than that in the $C$ group $(p<0.0001$, Fig. $2 a)$. Low viral loads were detected in the serum

(7 dpi) and tissues ( 15-22 days) of ducks in the V/C group only in the early stages of infection, and the viral load was significantly lower than that in the $C$ group. The spleen, with the highest viral load, was used for the isolation of NDPV (Figs. $2 b$ and 3 ).

\subsection{NDPV cannot be isolated from the immunized duck spleen}

The spleens of 29-day-old ducks (i.e., $21 \mathrm{dpi}$ in the V/C and $\mathrm{C}$ groups and 28 days post-vaccination [dpv] in the V group) were selected for NDPV isolation based on tissue viral load analysis. It was found that extracts of the spleens of ducks in the $C$ group could infect and kill the 9-day-old embryonated Cherry 
Valley duck eggs, and subcutaneous hemorrhages, edema, and hemorrhagic beak and feet were observed in the dead duck embryos. In contrast, extracts of the spleens of ducks in both the $\mathrm{V}$ and $\mathrm{V} / \mathrm{C}$ groups did not show duck embryo infection, and the appearance of these ducks was not different from those in the $B$ group. PCR revealed specific NDPV-positive bands for the $C$ group, whereas no positive target bands could be detected for the other groups (Fig. 4).

\subsection{Vaccines can induce high levels of antibodies}

The antibody response specific for NDPV VP3 in the serum of all ducks was detected by ELISA. Similar antibody trends were detected in the $\mathrm{V}$ and $\mathrm{V} / \mathrm{C}$ groups; at 8 days $(7 \mathrm{dpv})$, the $\mathrm{OD}_{450 \mathrm{~nm}}$ values for the $\mathrm{V}$ and $\mathrm{V} / \mathrm{C}$ groups were $0.635 \pm 0.241$ and $0.702 \pm 0.118$, respectively, which were significantly higher than that recorded for the $C$ group $(0.193 \pm 0.027 ; p<0.01$ and $p<0.001$, respectively). Furthermore, the levels of specific antibodies in the $V$ and $V / C$ groups exhibited a tendency to increase with time, with $O D_{450 \mathrm{~nm}}$ $>1$ at 22 days $(21 \mathrm{dpv})$. For the $V$ group, the highest $\mathrm{OD}_{450 \mathrm{~nm}}$ recorded was $1.625 \pm 0.076$ at $49 \mathrm{dpv}$, and the value was maintained at $1.431 \pm 0.189$ until $63 \mathrm{dpv}$ (Fig. 5a, b).

The VN titer was $>1: 2^{3}$ at $7 \mathrm{dpv}$, i.e., $50 \%$ of the duck embryos could be protected from death at a $1: 8$ dilution, after which the VN titer gradually increased to $>1: 2^{5}$ at $14 \mathrm{dpv}, 1: 2^{6}$ at $21 \mathrm{dpv}, 1: 2^{6.8}$ at $28 \mathrm{dpv}$, $1: 2^{7.7}$ at $35 \mathrm{dpv}$, and $1: 2^{8.5}$ at $42 \mathrm{dpv}$ (Fig. $5 \mathrm{c}$ ).

\subsection{No pathological lesions are formed in immunized ducks}

The histochemical analysis of the duck tissues from the $\mathrm{V}$ and $\mathrm{V} / \mathrm{C}$ groups showed structurally intact tissues with no obvious pathological abnormalities, similar to that of ducks in the B group. However, there were significant pathological changes in the spleen and lungs of ducks in the $\mathrm{C}$ group, including unclear boundaries of red and white marrow and a large number of apoptotic necrosis areas, nuclear fragmentation and lysis in the spleen, and obvious hemorrhage in the lung along with a large number of inflammatory cell nuclear fragmentations, light coloration, unclear boundaries of the lung lobules, and broken capillary arms forming emphysema (Fig. 6).

\section{Discussion}

SBDS mainly causes severe growth retardation in Cherry Valley ducks, Pekin ducks, hybrid Muscovy ducks, and sheldrakes. Clinically, the affected ducks primarily show typical pathological symptoms of atrophy, and shortened beaks and swollen and outstretched tongues; however, it is generally difficult to reproduce these typical symptoms under artificial infection conditions [1, 12], which makes the evaluation of vaccines for this disease difficult. In this study, a vaccine was evaluated mainly in terms of clinical symptoms, viremia, virus excretion, and virus isolation. It was shown that the NDPV isolates that were prevalent in European countries had difficulties in replicating typical clinical symptoms, which may be related to differences in pathogenicity of different strains, feeding conditions, and challenge doses. 
Studies have shown that the attenuated GPV vaccine is excreted in feces over a long period [15], and GPV is very resistant to chemical and physical treatments [13]; thus, it is very difficult to eradicate GPV completely from infected farms. Hence, we focused on developing an inactivated virus vaccine for SBDS, which is more advantageous in terms of safety. Generally, the immunization procedure for the GPV vaccine is to immunize the mother goose so that the offspring can obtain immune protection, but research shows that the immune antibodies obtained by the offspring can generally only be maintained for 2-3 weeks $[4,6]$, and thus, the offspring may still cause infection for a long time until slaughter $(2-3$ months). Therefore, using an inactivated virus vaccine to strengthen the immunity of the offspring is an effective means of disease prevention and control. It is also suggested that the timing is important when vaccinating ducklings, with the earlier being the better. Therefore, we chose to immunize ducks at 1 day of age in this study. The inactivated virus vaccine developed in this study produced NDPV-VP3-specific antibodies detected at an $\mathrm{OD}_{450 \mathrm{~nm}} \sim 0.63$, with more than $1: 2^{3}$ of $\mathrm{VN}$ antibodies in ducks at $7 \mathrm{dpv}$. The immunized ducks could resist virulent strain attacks, indicating that the inactivated virus vaccine could induce the immunized ducks to produce a good humoral immune response in a short time postvaccination. The immunized ducks produced serum-specific antibodies with an $\mathrm{OD}_{450 \mathrm{~nm}}>1$ and VN antibodies $>1: 2^{6}$ at $21 \mathrm{dpv}$, showing good immunogenicity. In addition, inactivated virus vaccines are highly safe, inexpensive, and still occupy a large market in the field of veterinary vaccines.

The challenge protection test demonstrated that the vaccine could induce high levels of VN antibodies after immunization, which could effectively inhibit the replication of NDPV and protect the immunized ducks from the NDPV virulent strain challenge. Only one (1/28) duck exhibited a fracture-prone leg bone; thus, the vaccine provided $96 \%$ protection. NDPV could not be isolated from the spleens of ducks in the $V$ and $\mathrm{V} / \mathrm{C}$ groups, which provided a favorable assurance of the immune efficacy of the inactivated virus vaccine.

In conclusion, the inactivated NDPV-DS15 vaccine for SBDS developed in our study induced a good humoral immune response, which not only protected the ducks against the virulent strain of NDPV, but also continuously inhibited the replication of NDPV and reduced the risk of virus transmission. NDPVDS15 seemed to be a good candidate for an inactivated NDPV vaccine, and it would be a powerful tool for the prevention and control of SBDS.

\section{Abbreviations}

dpi: days post-infection; dpv: days post-vaccination; H\&E: hematoxylin and eosin; $E_{2} D_{50}: 50 \%$ embryo lethal dose; GPV: goose parvovirus; NDPV: novel duck parvovirus; qPCR: quantitative real-time PCR; SBDS: short beak and dwarf syndrome; VN: virus neutralizing

\section{Declarations}

\section{Funding}


This work was supported by the key research project of national science and technology (Grant numbers 2016YFD0500108, 2016YFD0501003) and the Chinese Natural Sciences Foundation (Grant number 31672572).

\section{Conflicts of interest}

The authors have no relevant financial or non-financial interests to disclose.

\section{Ethics approval}

All animal experiments were approved by the Animal Welfare and Ethics Committee of Shanghai Veterinary Research Institute, Chinese Academy of Agricultural Sciences (approval number SHVRI-ZD2019-032).

\section{References}

1. Chen H, Dou Y, Tang Y, Zheng X, Niu X, Yang J, Yu X, Diao Y (2016) Experimental reproduction of beak atrophy and dwarfism syndrome by infection in cherry valley ducklings with a novel goose parvovirus-related parvovirus. Veterinary microbiology 183:16-20.

https://doi.org/10.1016/j.vetmic.2015.11.034

2. Chen S, Wang S, Cheng X, Xiao S, Zhu X, Lin F, Wu N, Wang J, Huang M, Zheng M, Chen S, Yu F (2016) Isolation and characterization of a distinct duck-origin goose parvovirus causing an outbreak of duckling short beak and dwarfism syndrome in China. Archives of virology 161:2407-2416. https://doi.org/10.1007/s00705-016-2926-4

3. Fan W, Sun Z, Shen T, Xu D, Huang K, Zhou J, Song S, Yan L (2017) Analysis of Evolutionary Processes of Species Jump in Waterfowl Parvovirus. Frontiers in microbiology 8:421. https://doi.org/10.3389/fmicb.2017.00421

4. Gough RE (1984) Application of the agar gel precipitin and virus neutralisation tests to the serological study of goose parvovirus. Avian pathology : journal of the WVPA 13:501-509. https://doi.org/10.1080/03079458408418551

5. Jin M, Feng C, Wang X, Zhang D (2019) Molecular evidence of goose-parvovirus-related abnormal molting in Pekin ducks. Archives of virology 164:2837-2841. https://doi.org/10.1007/s00705-01904393-9

6. Kisary J (1977) Immunological aspects of Derzsy's disease in goslings. Avian pathology : journal of the WVPA 6:327-334. https://doi.org/10.1080/03079457708418242

7. Lee MS, Cohen B, Hand J, Nokes DJ (1999) A simplified and standardized neutralization enzyme immunoassay for the quantification of measles neutralizing antibody. Journal of virological methods 78:209-217. https://doi.org/10.1016/S0166-0934(98)00178-5

8. Li C, Li Q, Chen Z, Liu G (2016) Novel duck parvovirus identified in Cherry Valley ducks (Anas platyrhynchos domesticus), China. Infection, genetics and evolution : journal of molecular 
epidemiology and evolutionary genetics in infectious diseases 44:278-280.

https://doi.org/10.1016/j.meegid.2016.07.020

9. Li P, Lin S, Zhang R, Chen J, Sun D, Lan J, Song S, Xie Z, Jiang S (2018) Isolation and characterization of novel goose parvovirus-related virus reveal the evolution of waterfowl parvovirus. 65:e284-e295. https://doi.org/10.1111/tbed.12751

10. Lu YS, Lin DF, Lee YL, Liao YK, Tsai HJ (1993) Infectious bill atrophy syndrome caused by parvovirus in a co-outbreak with duck viral hepatitis in ducklings in Taiwan. Avian diseases 37:591-596. https://pubmed.ncbi.nlm.nih.gov/8395811/

11. Ning K, Wang M, Qu S, Lv J, Yang L, Zhang D (2017) Pathogenicity of Pekin duck- and goose-origin parvoviruses in Pekin ducklings. Veterinary microbiology 210:17-23. https://doi.org/10.1016/j.vetmic.2017.08.020

12. Palya V, Zolnai A, Benyeda Z, Kovács E, Kardi V, Mató T (2009) Short beak and dwarfism syndrome of mule duck is caused by a distinct lineage of goose parvovirus. Avian pathology : journal of the WVPA 38:175-180. https://doi.org/10.1080/03079450902737839

13. Schettler $\mathrm{CH}$ (1973) Virus hepatitis of geese. 3. Properties of the causal agent. Avian pathology : journal of the WVPA 2:179-193. https://doi.org/10.1080/03079457309353795

14. Shen H, Zhang W, Wang H, Zhou Y, Shao S (2015) Identification of recombination between Muscovy duck parvovirus and goose parvovirus structural protein genes. Archives of virology 160:2617-2621. https://doi.org/10.1007/s00705-015-2541-9

15. Takehara K, Saitoh M, Kiyono M, Nakamura M (1998) Distribution of attenuated goose parvoviruses in Muscovy ducklings. The Journal of veterinary medical science 60:341-344. https://doi.org/10.1292/jvms.60.341

16. Wan C, Liu R, Chen C, Cheng L, Shi S, Fu G, Chen H, Fu Q, Huang Y (2019) Novel goose parvovirus in domestic Linwu sheldrakes with short beak and dwarfism syndrome, China. 66:1834-1839. https://doi.org/10.1111/tbed.13280

17. Wang D, Shi J, Yuan Y, Zheng L, Zhang D (2013) Complete sequence of a reovirus associated with necrotic focus formation in the liver and spleen of Muscovy ducklings. Veterinary microbiology 166:109-122. https://doi.org/10.1016/j.vetmic.2013.05.022

18. Xiao S, Chen S, Cheng X, Lin F, Wang S, Zhu X, Yu B, Huang M, Wang J, Wu N, Zheng M, Chen S, Yu F (2017) The newly emerging duck-origin goose parvovirus in China exhibits a wide range of pathogenicity to main domesticated waterfowl. Veterinary microbiology 203:252-256. https://doi.org/10.1016/j.vetmic.2017.03.012

19. Zadori Z, Erdei J, Nagy J, Kisary J (1994) Characteristics of the genome of goose parvovirus. Avian pathology : journal of the WVPA 23:359-364. https://doi.org/10.1080/03079459408419004

20. Zhou J, Tang A, Qi R, Liu G (2020) Development and preliminary application of a SYBR Green I fluorescence quantitative PCR assay for a novel duck parvovirus. Chinese Journal of Animal Infectious Diseases 28:47-51. https://kns.cnki.net/kcms/detail/detail.aspx?

FileName=ZSJB202004007\&DbName=CJFQ2020 


\section{Tables}

Table 1: Animal experimental design

\begin{tabular}{|c|c|c|c|c|c|}
\hline Group & V & C & $\mathrm{V} / \mathrm{C}$ & & B \\
\hline Age & vaccination & challenge & vaccination & challenge & प \\
\hline 1day & $\begin{array}{l}\operatorname{im} \rrbracket \\
5 \times 10^{3.75} E_{L D} 50 \\
\text { per duck }\end{array}$ & प & $\begin{array}{l}\operatorname{im} \rrbracket \\
5 \times 10^{3.75} E_{L D} 50 \\
\text { per duck }\end{array}$ & & $\begin{array}{l}\text { im, } \\
0.4 \mathrm{~mL} \\
\text { PBS }\end{array}$ \\
\hline 2days & A & A & A & & A \\
\hline 5days & A & A & A & & A \\
\hline 8days & $A, B, S$ & $\begin{array}{l}\text { A; im, } \\
4 \times 10^{4.75} E D_{50} \text { per } \\
\text { duck }\end{array}$ & $A$, & $\begin{array}{l}\text { im, } \\
4 \times 10^{4.75} E_{L D} 50 \\
\text { per duck }\end{array}$ & $\begin{array}{l}\text { im, } \\
0.4 \mathrm{~mL} \\
\text { PBS }\end{array}$ \\
\hline 9days & A & A & A & & A \\
\hline 11 days & A & $A$ & A & & A \\
\hline 15 days & $A, B, S, T$ & $A, B, S, T$ & $A, B, S, T$ & & $A, B, S, T$ \\
\hline 22 days & $A, B, S, T$ & $A, B, S, T$ & $A, B, S, T$ & & $A, B, S, T$ \\
\hline 28days & $A, B, S, T$ & $A, B, S, T$ & $A, B, S, T$ & & $A, B, S, T$ \\
\hline 36 days & $A, B, S, T$ & $A, B, S, T$ & $A, B, S, T$ & & $A, B, S, T$ \\
\hline 43days & $A, B, S, T$ & $A, B, S, T$ & $A, B, S, T$ & & $A, B, S, T$ \\
\hline 55days & S & प & प & & प \\
\hline 64days & $S$ & ए & प & & प \\
\hline
\end{tabular}

im: intramuscular injection; A: anal swab; B: body weight; S: serum; T: tissue; V: vaccination; C: challenge control; V/C: vaccination-challenge; B: blank control; ELD50: 50\% embryo lethal dose; Three ducks were selected randomly from each group and euthanized; tissues sampled include the heart, liver, pancreas, lung, kidney, duodenum, and thymus.

Table 2 : Evaluation of clinical symptoms of short beak and dwarf syndrome upon administering inactivated novel duck parvovirus vaccine 


\begin{tabular}{lllll} 
clinical symptoms & $\mathrm{V}$ & $\mathrm{C}$ & $\mathrm{V} / \mathrm{C}$ & $\mathrm{B}$ \\
\hline mental atrophy & - & $+\llbracket 5 / 28 \rrbracket$ & - & - \\
\hline feather disheveled & - & $+++(18 / 28)$ & - & - \\
\hline Fractures of the leg bones & - & $++++(28 / 28)$ & $+(1 / 28)$ & - \\
\hline Paralysis & - & $+(2 / 28)$ & - & - \\
\hline Diarrhea & - & $+++(15 / 28)$ & - & - \\
\hline Mental commiseration & - & $+(4 / 28)$ & - & - \\
\hline Discharge around eyes & - & $+++(15 / 28)$ & - & -
\end{tabular}

"-": no change; "+": mild; "+++": moderate; "++++": marked; V: vaccination; C: challenge control; V/C: vaccination-challenge; $\mathrm{B}$ : blank control

\section{Figures}

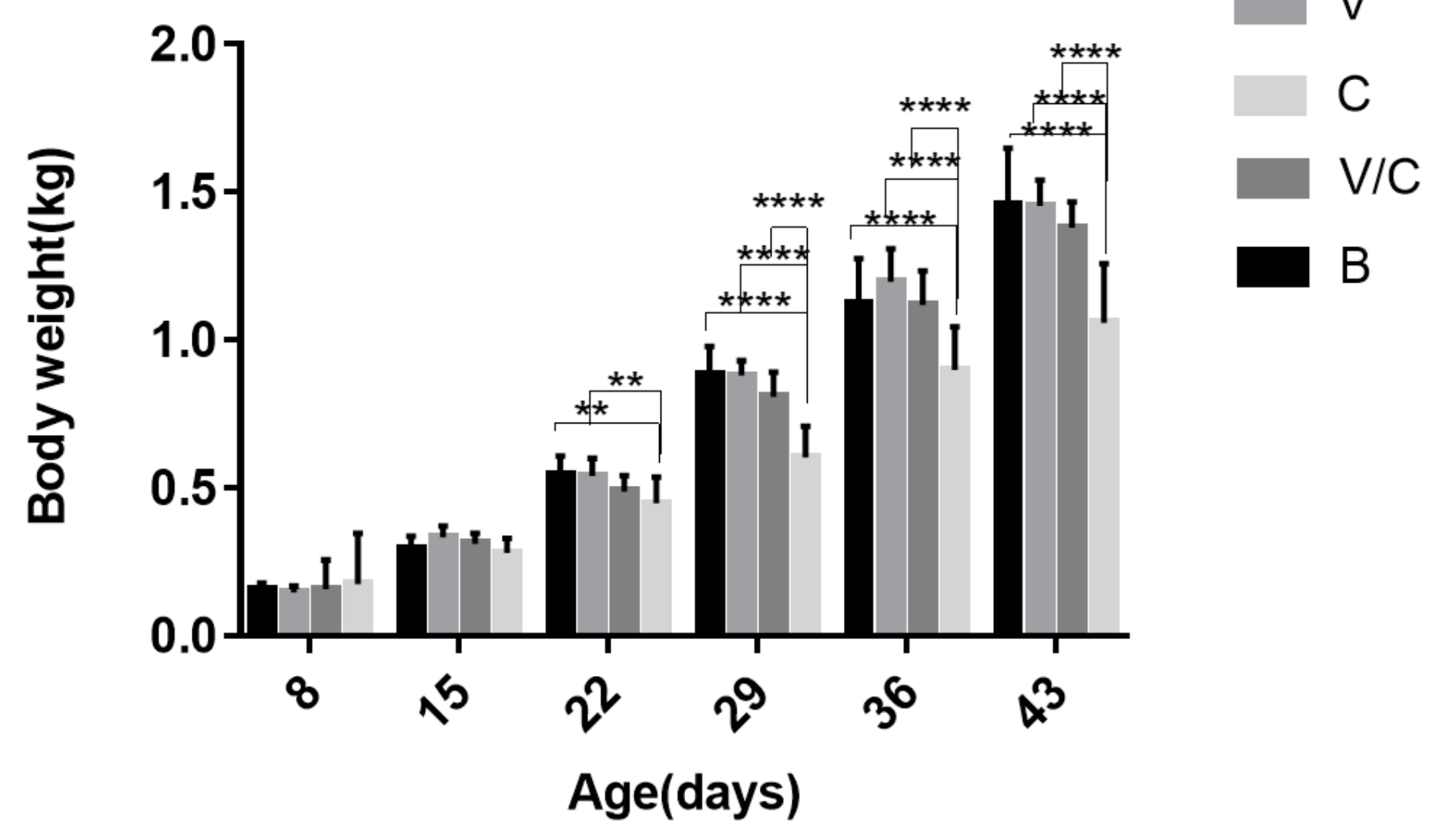

Figure 1 
Body weight of the ducks in the four different experimental groups over time. $\mathrm{V}$ : vaccination; $\mathrm{C}$ : challenge control; V/C: vaccination-challenge; B: blank control. Significance is shown by ${ }^{*} p<<0.01$, ${ }^{\star * \star *} p<0.0001$

a

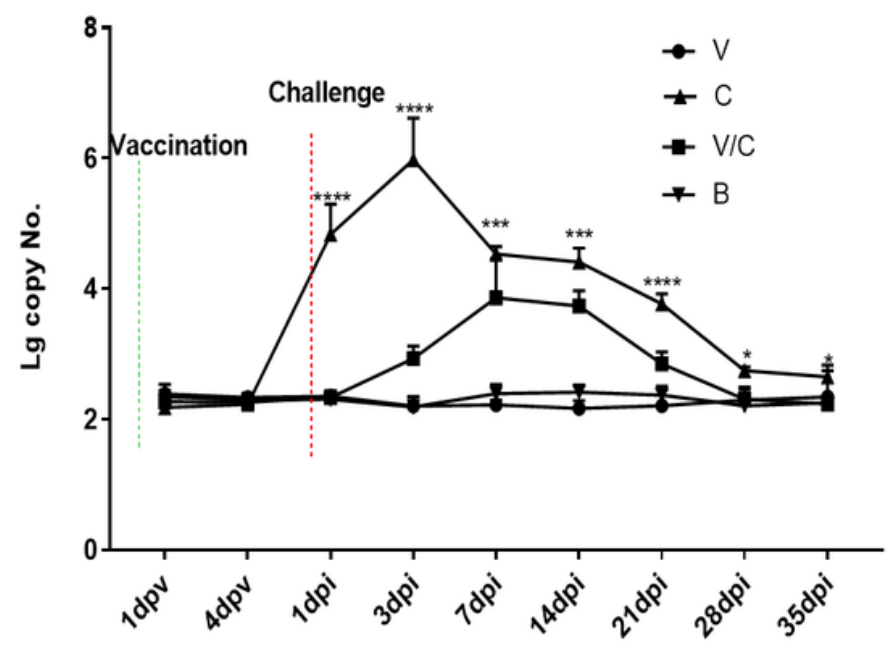

Days post vaccination or infection b

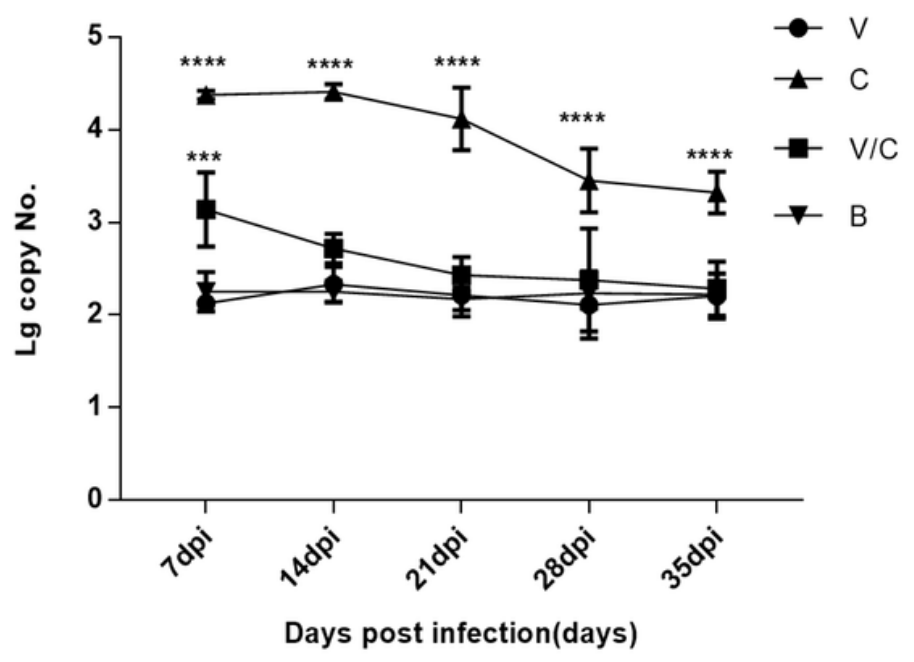

Figure 2

Detection of novel duck parvovirus (NDPV) load. DNA copies are calculated as mean \pm standard deviation. (a) NDPV load in anal swabs; $\mathrm{n}=4$ in each group at each time point. *: significant difference between the $C$ and $V / C$ groups; ${ }^{* \star} p<0.001,{ }^{\star \star \star \star} p<0.0001$. (b) NDPV load in serum; $n=4$ in each group at each time point. $* \star \star *$ : significant difference between the $\mathrm{V} / \mathrm{C}$ and $\mathrm{C}$ groups, $\mathrm{p}<0.0001$. V: vaccination; $\mathrm{C}$ : challenge control; $\mathrm{V} / \mathrm{C}$ : vaccination-challenge; $\mathrm{B}$ : blank control 

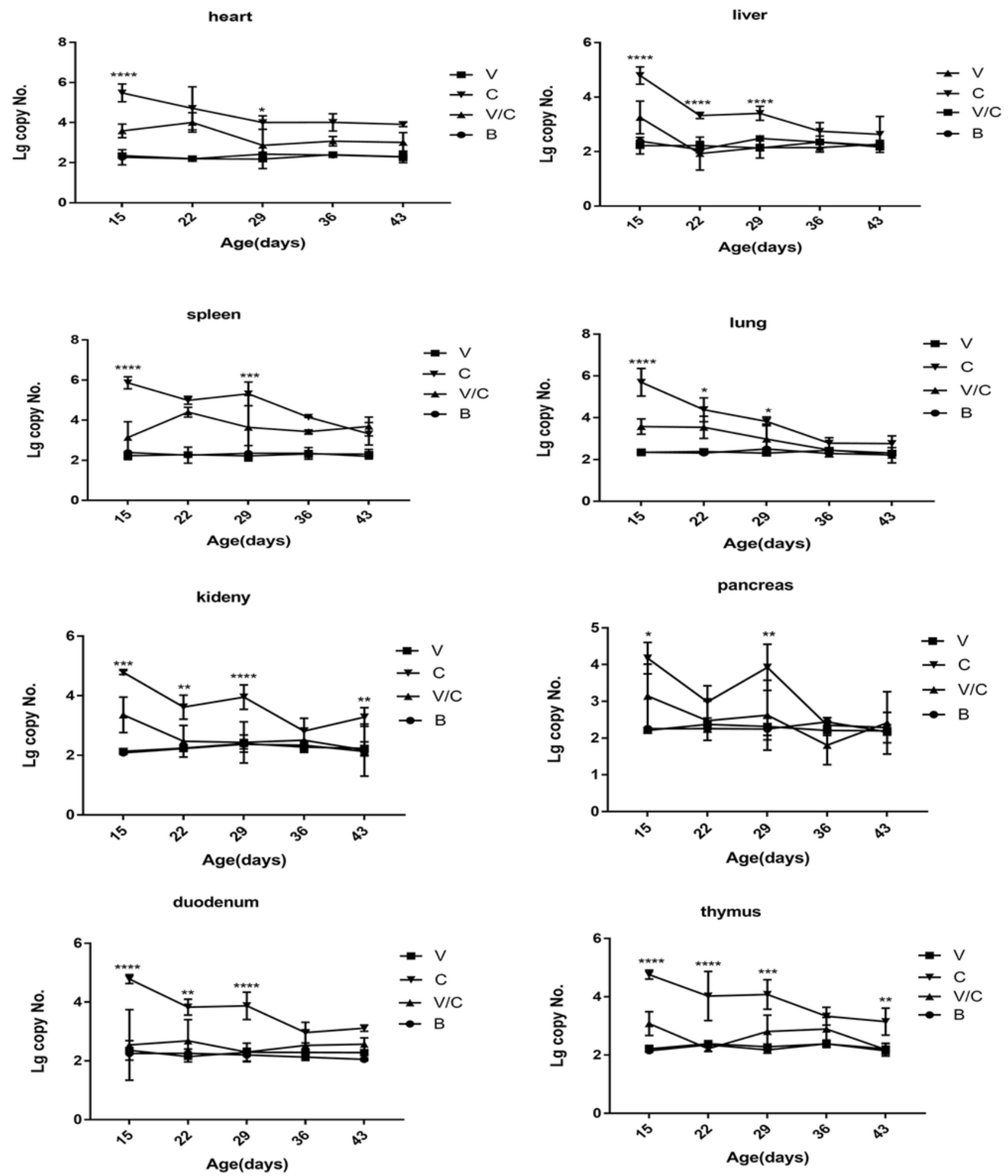

\section{Figure 3}

Novel duck parvovirus load in duck tissues. DNA copies of 3 samples from each group at each time point were analyzed, and data are presented as mean \pm standard deviation. $*$ : significant difference between the V/C and C groups; ${ }^{\star} p<0.05,{ }^{\star \star} p<0.01,{ }^{\star \star \star} p<0.001,{ }^{\star \star \star \star} p<0.0001$. V: vaccination; $\mathrm{C}$ : challenge control; V/C: vaccination-challenge; B: blank control 


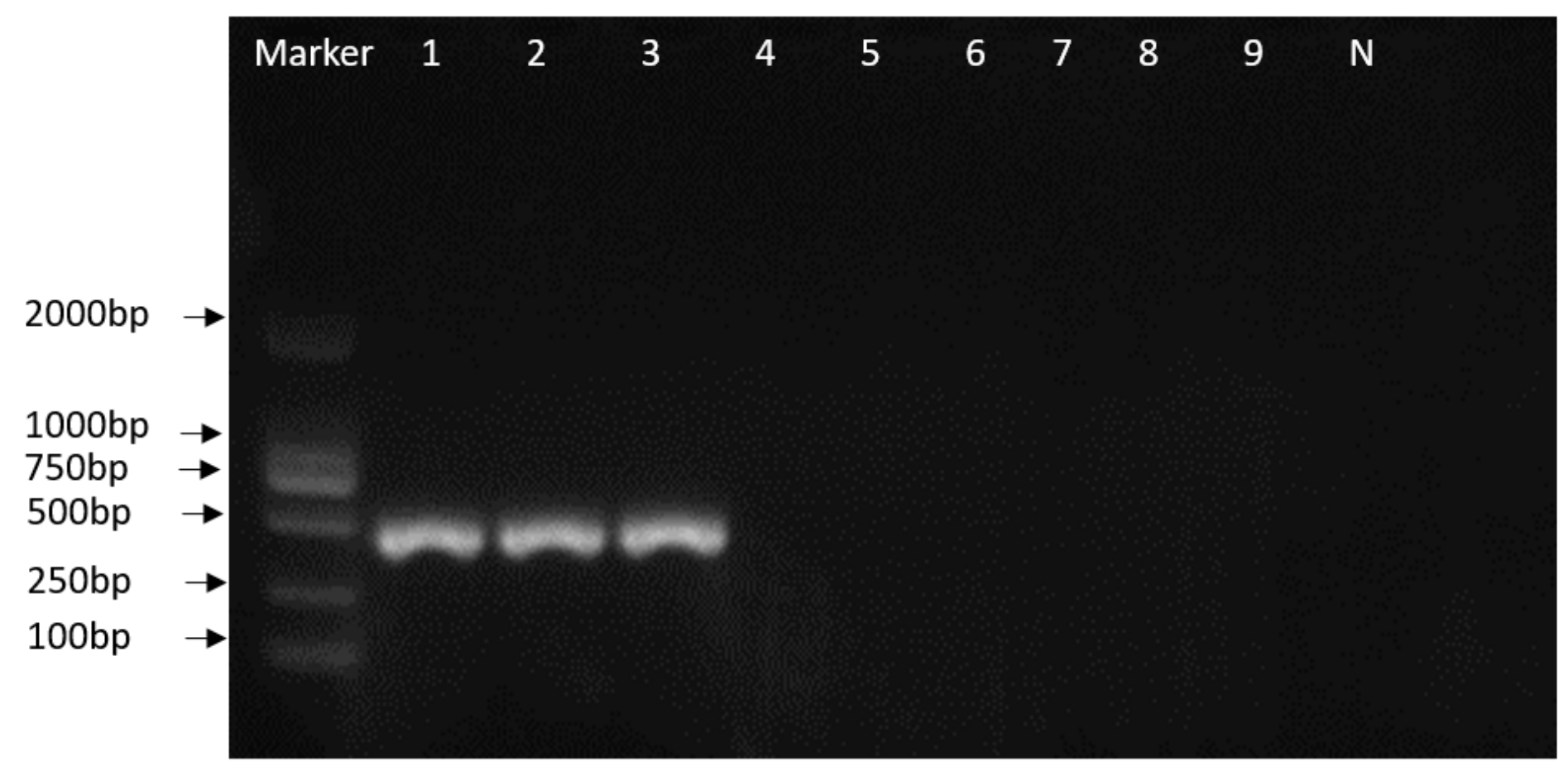

\section{Figure 4}

PCR detection of novel duck parvovirus in DNA isolated from the spleens of ducks in the experimental groups. Lanes 1 3: challenge control group, lanes 4 6: vaccination-challenge group, lanes 7 9: vaccine immune group, lane $\mathrm{N}$ : negative control 

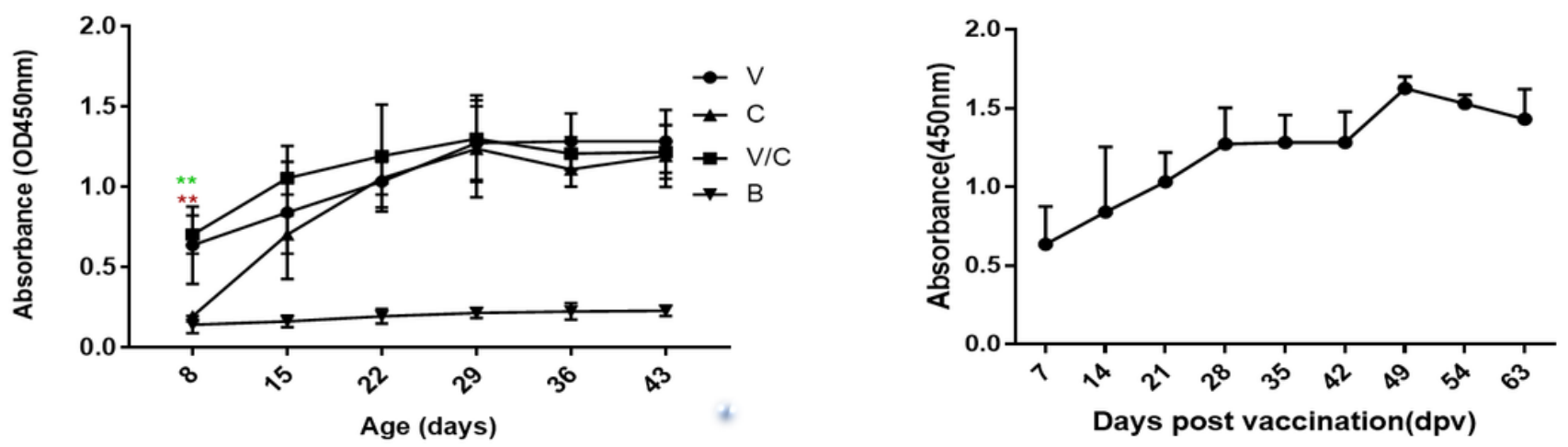

c

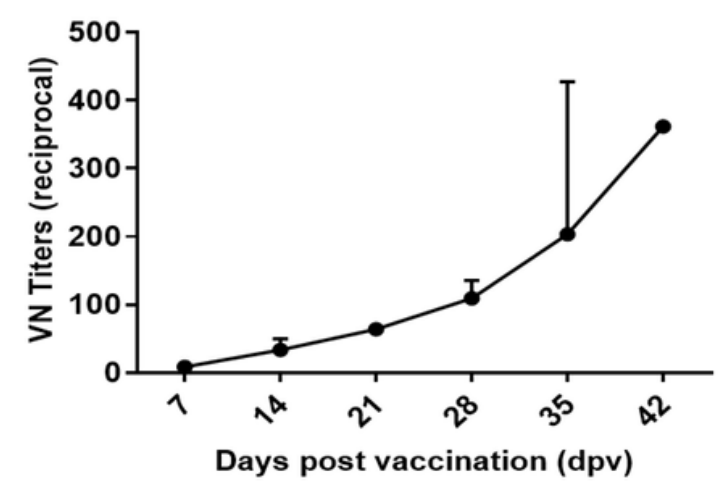

Fig. 5 Antibodies in serum of ducks after vaccination and infection. (a) Detection of novel duck parvovirus (NDPV)-VP3-specific antibody in serum of ducks from each group at each time point $(\mathrm{n}=5)$. **: significant difference between the $\mathrm{V}$ and $\mathrm{C}$ groups; ***: significant difference between the $\mathrm{V} / \mathrm{C}$ and $\mathrm{C}$ groups. (b) Duration of immunity in ducks in each group at each time point $(n=5)$. (c) Virus neutralizing antibody titers measured over time by a virus neutralization test. Each point represents the reciprocal of the virus neutralizing antibody titer $(\log 2)$ of serum \pm standard deviation $(n=6)$. V: vaccination; C: challenge control; V/C: vaccination-challenge; B: blank control; VN: virus neutralizing

\section{Figure 5}

See image above for figure legend 

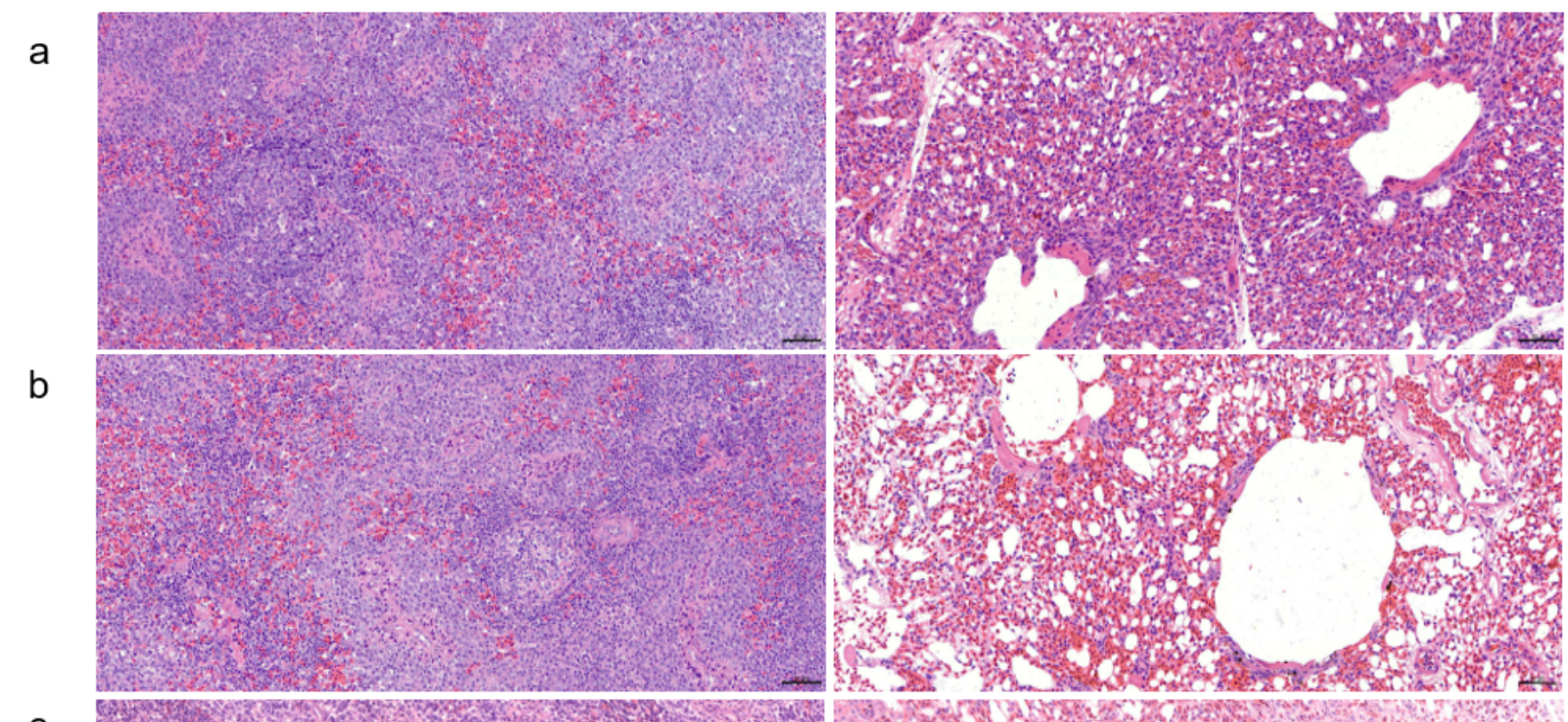

e

C
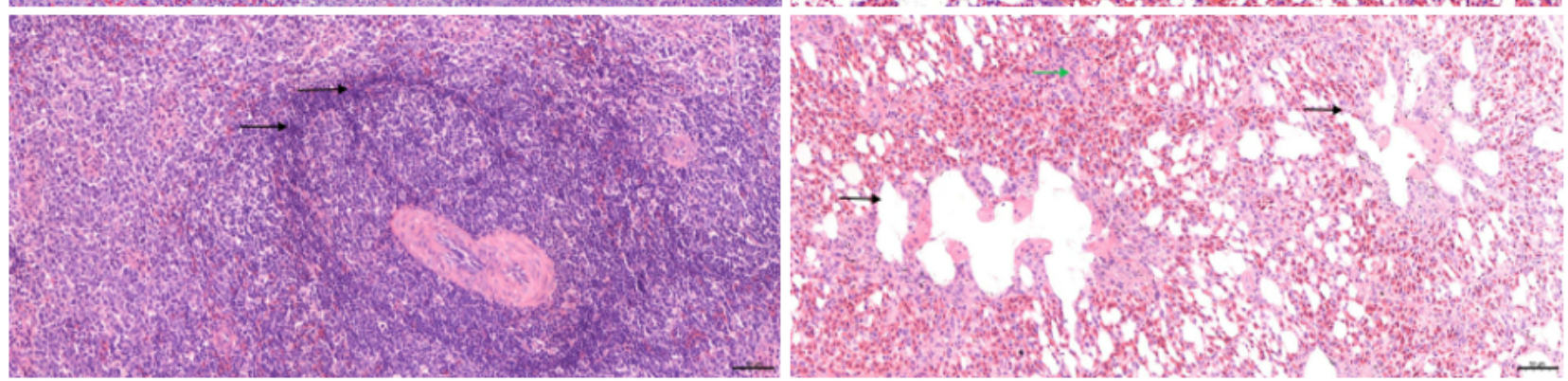

d
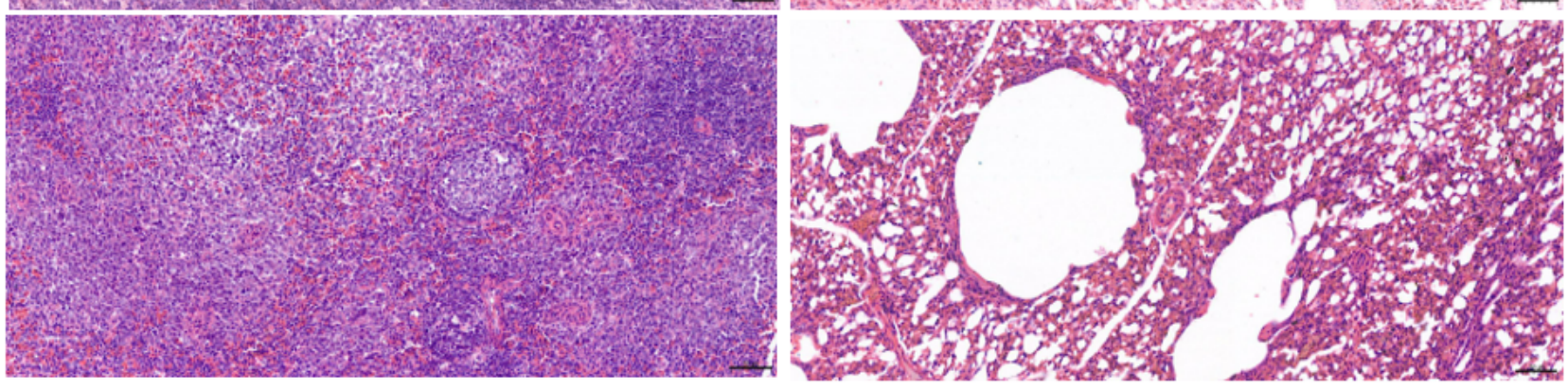

h

\section{Figure 6}

Microscopic lesions stained with hematoxylin \& eosin in tissues of ducks belonging to different experimental groups. ( $a$ and e) The spleen and lung of the ducks in the vaccination group, respectively; (b and $f$ ) the vaccination/challenge group; ( $c$ and $g$ ) the challenge control group; and ( $d$ and $h$ ) the blank control group. Apoptotic necrosis, nuclear fragmentation, and lysis in the spleen are indicated by black arrows (c); inflammatory cell nuclear fragmentation and light coloration in the lung (green arrow) as well as broken capillary arms forming emphysema (black arrows) are shown (g); bar $=50 \mu \mathrm{m}$ 